\title{
A Real-Time Thermal Test Platform for Under- water Complex Structures and Heat Transfer Analysis
}

\author{
http://dx.doi.org/10.3991/ijoe.v9iS2.2564 \\ Kuang Ding ${ }^{1}$, Hongwu Zhu ${ }^{1}$, Xiangling Kong ${ }^{2}$ and Biao $\mathrm{Hu}^{1}$ \\ ${ }^{1}$ China University of Petroleum, Beijing, China \\ ${ }^{2}$ China Petroleum Technology and Development Corporation, Beijing, China
}

\begin{abstract}
In order to conduct an effective and reasonable heat transfer analysis, a real-time thermal test platform was established, which consists of two flow loops, the heating system, the data acquisition system, the automatic data processing software and the relative piping system. Based on this platform, a typical T-type deadleg and a gate valve assembly are adopted to investigate their heat transfer characteristics. The experiment data are compared with the numerical calculation with great good agreements. For further application, this real-time thermal test platform could be used for cool down analysis and thermal insulation assessment. Ultimately, promotional values for similar and even much larger scale complex underwater structures could be found in this study.
\end{abstract}

Index Terms - heat transfer, real-time experiment, thermal test, underwater structure.

\section{INTRODUCTION}

Underwater complex thermal-fluid system is commonly used for subsea hydrocarbon production, such as subsea Xmas tree, subsea manifold, and underwater flow line and pipe line. In order to improve the reliability and flow assurance of the underwater complex thermal-fluid system during the whole production cycle, even more than 20 years, a real-time thermal test platform for these typical contractible models and an effective and reasonable heat transfer analysis are necessary at the initial design stage. In addition, this platform could provide experiment data for numerical verification and experimental analysis.

Zabaras [1] made 2-D finite element analysis of the heat transfer problems for the subsea Xmas tree and the subsea pipeline joints. Janoff et al. [2] analyzed the heat transfer problems of the valve blocks, emphasizing the importance of 3-D models and boundary conditions to the numerical calculation. Aarnes [3] finished heat transfer analysis and a full-scale experiment for the subsea Xmas tree, the connector and the manifold of the Dalia subsea oilfield. In the article, a method of reducing the error of the finite element calculation by modifying the fluid thermal conductivity was proposed. Davalath [4] used three-dimensional finite element method to establish a subsea Xmas tree computational model, of which the working pressure was $69 \mathrm{MPa}$ and $103.5 \mathrm{MPa}$, and completed the heat transfer calculation under the conditions of thermal insulation. Sorbye et al. [5] conducted heat transfer calculations and insulation analysis for the subsea manifold, and demonstrated the feasibility of their calcula- tion method by full-size experiments. The article focused on the CFD based methods, and emphasized the factors that should be taken account in the calculation process, such as turbulence models, the grid, time step, etc. Carré [6] adopted the finite element method in the heat transfer calculations of the vertical Xmas tree of the Moho Bilondo oilfield in West Africa. Yaojun Lu [7] proposed the concept of the coupling calculation for subsea equipment, but no specific calculation method and verification data was given.

From the above discussion, no enough experimental work embedded in the numerical analysis since the test data is the foundation towards numerical computation. There is much room for development of both numerical and experimental heat transfer analysis of the complex subsea thermal-fluid system. Therefore, a real-time thermal test system was established for underwater complex structures. Additionally, considering the T-type deadleg and gate valve assembly is the most indispensable part for subsea equipment and even the most common underwater thermal-fluid system with special heat transfer characteristics, they are adopted to verify such specific underwater heat transfer problem. Furthermore, this article has greater promotional value for the heat transfer calculation and experiment of similar and even much larger scale complex subsea thermal-fluid system.

\section{Thermal TeSt PALTFORM DESIGN}

\section{A. Experimental Setup}

Figure 1 shows a sketch of the real-time heat transfer test system with inner underwater structures. One can see two obvious flow loops, namely, the hot water flow indicated by red color and the cold water flow marked by blue color. For the hot flow loop, the water is heated by a temperature regulated water bath, and then 1-in hose is used to connect the underwater valve and the water bath. Two ball valves and one glass rotameter are installed to control and monitor the volume flow rate, respectively. Meanwhile, the cold flow loop consists of a pump, a piping system, and two reservoirs (a big water tank and a long water channel). The big water tank is placed on the ground and its total volume is $3 \mathrm{~m}^{3}$. This tank is used to mix the water from the long square channel and guarantee the cold flow temperature is not increased. The long water channel has a square cross section, and is located above that water tank. The pump is a centrifugal-type water pump with a rated power of $5 \mathrm{hp}$. The piping system is 


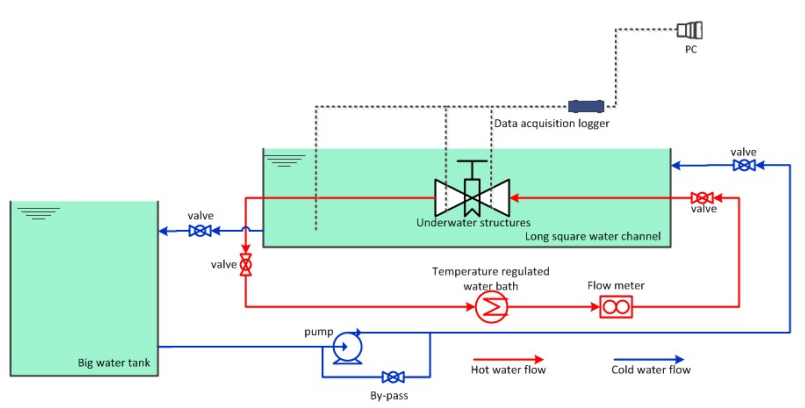

Figure 1. The layout of the real-time thermal test system

also made of 1-in hose, and two ball valves are used as pump suction and delivery valves. Furthermore, a plate with uniform small holes is installed upstream of the long square channel, so as to provide a steady uniform flow by minimizing the lateral flow fluctuations and unsteady flow oscillations. For this real-time thermal test platform, the underwater structures could be changed easily. The PC is far away from the flow system and the data acquisition could be operated friendly.

\section{B. Underwater Structures}

The underwater structures investigated in this study are located in the long square cold water channel. The first underwater structure investigated is a typical T-type deadleg, as illustrated in figure 2 . The deadleg is mounted vertically and connected with a horizontal main pipe, and both horizontal and vertical pipe have the same inner diameter of 1 inch. For this case, the length of the deadleg is ten times long than that of the inner diameter so as to whole temperature distribution within this blind vertical pipe. Generally, the velocity and temperature is becoming much smaller towards the lower end as it is closed and far away from the horizontal main pipe [8]. In order to obtain the internal fluid temperature, eight holes are drilled to install the thermocouples. The other underwater structure researched in this study is a gate valve assembly, as seen in figure 3. It mainly includes a lower valve body and an upper valve cover, and 4 bolts are used to connect the valve cover and the valve body. The internal structure diagram is also given. One can see the valve stem and the valve plate are located in the center of the valve assembly. In addition, a closed volume is present between the valve cover and the valve body. The underwater gate valve assembly is a complex thermal-fluid coupling system with multi-component and multi-computation domain [9].

\section{Data Measurements}

The water is heated by the temperature regulated water bath. The temperature and volume flow rate are rated at 50 ${ }^{\circ} \mathrm{C}$ and $20 \mathrm{~L} / \mathrm{min}$, respectively. For the cold flow, the volume flow rate is regulated by the pump and the by-pass, and the temperature depends on the room temperature, which are $840 \mathrm{~L} / \mathrm{min}$ and $12{ }^{\circ} \mathrm{C}$, respectively. The thermocouples of type $\mathrm{T}$ class 1 (temperature error is less than $1{ }^{\circ} \mathrm{C}$ ) are installed to obtain the surface temperature of the solid structures and the temperature of the fluid within them. It is noticed that all thermocouples are packaged with three different kinds of outer shells, as seen in figure 4, which dimensions are M6 $\times 1 \mathrm{~mm}, \mathrm{M} 8 \times 1.5 \mathrm{~mm}$ and 2 $\mathrm{mm} \times 6 \mathrm{~mm}$, respectively. The lead wire is 5 meters long so as to make the data acquisition system is far from the water circulation system.

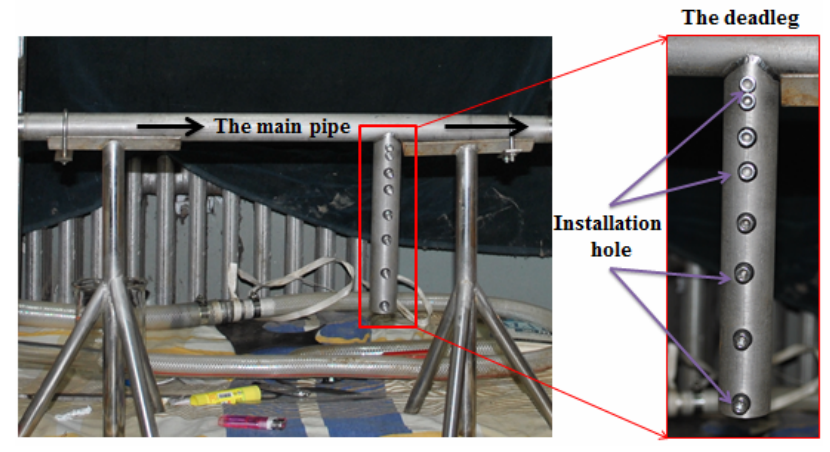

Figure 2. The deadleg and the distribution of thermocouple holes

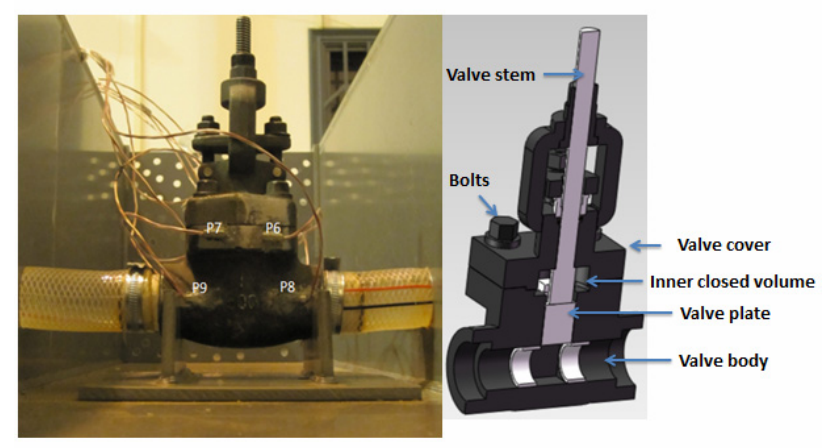

Figure 3. The underwater gate valve and its internal structure

Take the valve assembly as an example, when the hot water flow passes the internal surfaces of the gate valve, the heat is transferred to the solid valve body and lost continuously towards to ambient cold water. Eight thermocouples are located on the windward surface and leeward surface, respectively. Additional, two PT100 thermal resistance temperature sensors are fixed in the long square channel to monitor the cold flow temperature.

In order to make the visualization of experiment data, the data acquisition software programmed based on VB was installed in the PC to plot the data change tendency. Figure 5 gives the interface. The data acquisition software could obtain 15 groups data at the same time and the data could be shown in curves within the small windows. During the experiment process, data measurements and hot water circulation are commenced about 20 minutes after the water is heated by the water bath. Ultimately, the unchanged temperature data is obtained and recorded by the computer via data acquisition loggers after one and a half hours.

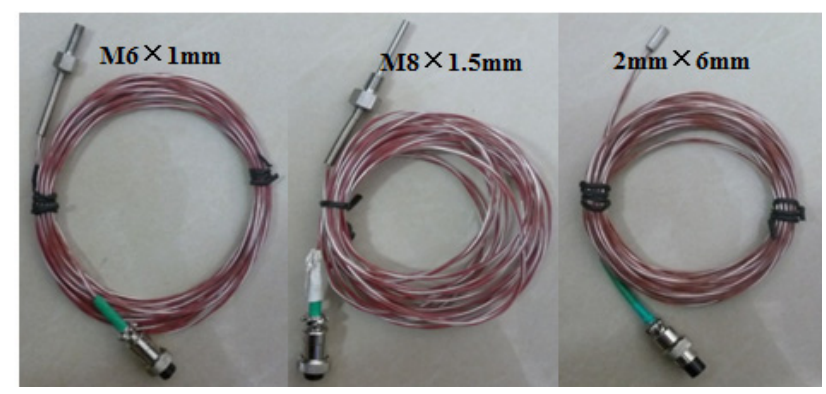

Figure 4. The thermocouples and three kinds of outer shells 


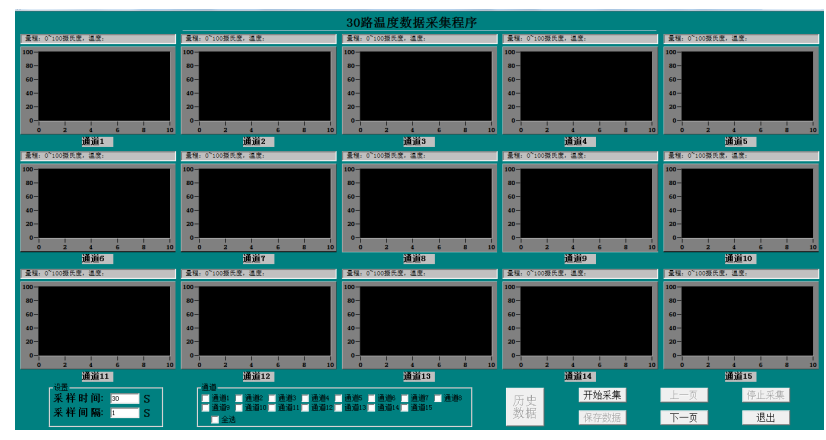

Figure 5. The data acquisition software interface

\section{NUMERICAL METHOD}

Numerical calculations for both deadleg and valve assembly were conducted so as to compare with the experiment data. Based on the commercial CFD package FLUENT and the control volume method, the standard $k-\varepsilon$ turbulence model in combination with LRNM [10] is utilized in all calculations. The second order upwind differencing scheme is used for convective terms and terms in equations for turbulent quantities and energy equation. Second order central differencing scheme is adopted for diffusion terms. The SIMPLE algorithm is used for coupling the pressure and velocity terms. Convergence of the computational solution is determined based on scaled residuals for the continuity, momentum and energy equations. The scaled residuals for solution convergence are set to $10^{-5}$ for all governing equations except the energy equation. The residual for energy equation is set to $10^{-8}$. The solution is considered to be converged when all of the scaled residuals are less than or equal to this prescribed value [11]. All the computations are carried out in an Intel Xeon ${ }^{\mathrm{TM}}(2.40 \mathrm{GHz})$ workstation computer.

\section{HEAT TRANSFER ANALYSIS}

When the inlet Reynolds number is fixed at 1900, the temperature distribution curve is given by figure 6 . As we can imagined a high temperature zone is located at the upper zone connecting with the deadleg opening. As the turbulent penetration, the fluid in this upper zone has a large velocity and forced convection heat transfer is the main reason for the appearance of this high temperature zone. For the rest place, a temperature transition zone locates just below the high temperature zone with a great temperature gradient. During this temperature transition zone, the temperature decreases from $45^{\circ} \mathrm{C}$ to $15^{\circ} \mathrm{C}$. The low temperature zone appears at the end of the deadleg. The temperature is almost $12{ }^{\circ} \mathrm{C}$ which is the same to the ambient cold water. Generally, a shorter lower temperature zone is required for industry application. Otherwise, a longer lower temperature zone could bring risks for solid deposition, corrosion, and sterilization, etc.

Figure 7 compares the temperature distribution of the central axis of the deadleg. The numerical results show the temperature distribution with three different temperature zones. That is, the high temperature zone locates from 0 $\mathrm{mm}$ to $75 \mathrm{~mm}$, the low temperature zone locates from 175 $\mathrm{mm}$ to the end, both are almost 3 times long of the inner diameter, leaving the temperature transition zone appears from $75 \mathrm{~mm}$ to $175 \mathrm{~mm}$. Meanwhile, the experiment data are marked with a good agreement. The maximum tem-

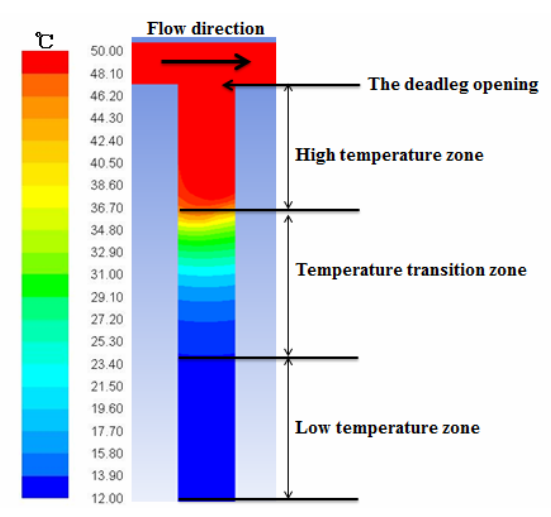

Figure 6. The temperature contours of the deadleg

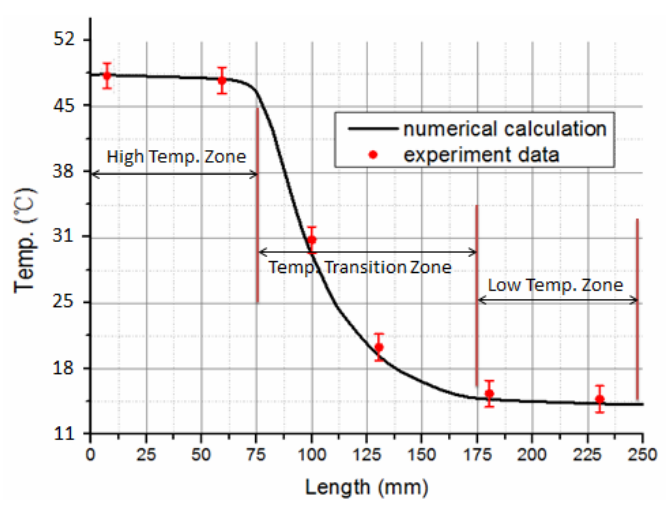

Figure 7. The temperature comparison of the deadleg

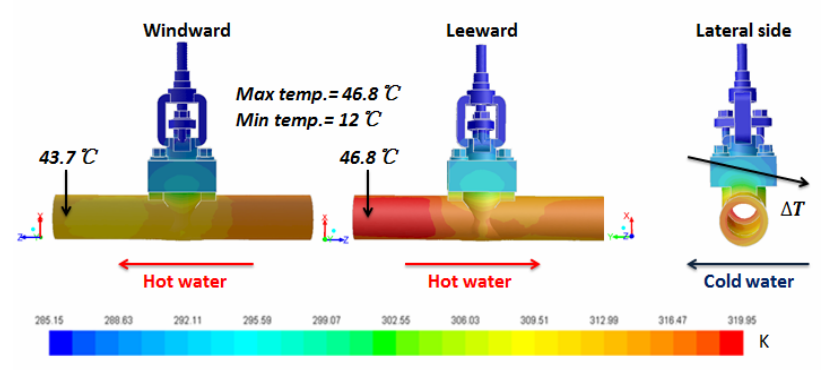

Figure 8. The temperature contours of the gate valve assembly

perature difference is less than $1{ }^{\circ} \mathrm{C}$, and all error bars cover the numerical results.

For the underwater valve assembly, figure 8 shows the temperature contours at external surfaces of valve body. Obviously, the temperature of the windward is lower than that of the leeward, and the maximum temperature difference could be up to $3{ }^{\circ} \mathrm{C}$ for the positions with same height. Thereby, a temperature gradient is present at the lateral surfaces between the windward and the leeward. Meanwhile, the cylinder surfaces of the valve body have the higher temperature, which is much higher than that of the rectangle surfaces of the valve body and surfaces of the upper cover. The maximum temperature is $46.8{ }^{\circ} \mathrm{C}$, which is located at the inlet position of the cylinder surfaces of the valve body. The minimum temperature, of course, appears on the top of the valve stem with a value of $12{ }^{\circ} \mathrm{C}$. Overall, the temperature decreases from bottom to up, along the hot water flow, and along the opposite position of the cold water flow.

The numerical results are compared with the experimental data. The detailed comparison is shown in table 1 . 
SPECIAL FOCUS PAPER

A Real-Time Thermal Test Platform for Underwater Complex Structures and Heat Transfer Analysis

TABLE I.

THE COMPARISON BETWEEN NUMERICAL SIMULATION AND THE EXPERIMENT RESULTS

\begin{tabular}{|l|c|c|c|c|c|c|c|c|c|c|}
\hline \multirow{2}{*}{ monitors } & \multicolumn{4}{|c|}{ Leeward } & \multicolumn{4}{c|}{ Windward } & \multicolumn{1}{c|}{ Lateral side } \\
\cline { 2 - 19 } & P1 & P2 & P3 & P4 & P6 & P7 & P8 & P9 & P5 & P10 \\
\hline Numerical results $\left({ }^{\circ} \mathrm{C}\right)$ & 21.2 & 20.7 & 39.4 & 37.9 & 19.4 & 19.1 & 37.0 & 35.5 & 24.2 & 23.7 \\
\hline Experiment results $\left({ }^{\circ} \mathrm{C}\right)$ & 21.8 & 21.2 & 38.1 & 36.5 & 20.4 & 20.1 & 36.3 & 34.4 & 23.7 & 23.2 \\
\hline Relative error* $(\%)$ & -2.88 & -2.47 & +3.32 & +3.90 & -4.83 & -4.89 & +2.04 & +3.26 & +2.11 & +2.29 \\
\hline
\end{tabular}

$*$ Relative error $=($ numerical results-experimental results) $/$ experimental results $\times 100 \%$

Among the ten packaged thermocouples, p5 and p10 are installed on the both lateral sides, $\mathrm{p} 1-\mathrm{p} 4$ are located on the leeward surface, and p6 - p9 are located on the windward surface. For the windward surfaces, the maximum error for the simulation results is $-4.89 \%$. And for the leeward surfaces, the the maximum error is $+3.90 \%$. For p5 and p10 which locate at the lateral surfaces, the relative error is $+2.11 \%$ and $+2.29 \%$, respectively. The numerical simulation could satisfactorily obtain the features of the temperature distribution of the outer surfaces when flow past the valve. The numerical results are accurate, and agree very well with the experimental results. In can be concluded the standard k- $\varepsilon$ turbulence model in combination with LRNM is suitable for such conjugate heat transfer problem. Specifically, this method is capable of resolving the boundary layer on complex coupled surfaces.

\section{CONCLUSIONS}

A real-time thermal test platform was established for thermal analysis of different kinds of complex underwater structures, which consists of two flow loops, the heating system, the data acquisition system, the automatic data processing software and the piping system. Based on this platform and commercial CFD code, a typical T-type deadleg and a gate valve assembly are adopted to investigate their underwater heat transfer problems. Both numerical and experimental results could obtain the temperature distribution characteristics with a good agreement. The real-time thermal test platform could be used for further steady and unsteady heat transfer analysis. This paper is also bringing promotional values for similar and even much larger scale complex underwater structures.

\section{ACKNOWLEDGEMENTS}

Thanks to the support of the Baoji oilfield machinery corporation. The authors also gratefully acknowledge the anonymous reviewers for their beneficial instructions and suggestions in improving this article.

\section{REFERENCES}

[1] G. J. Zabaras and J. F. Zhang, "Steady-state and Transient Thermal Performance of Subsea Hardware," SPE Drilling \& Completion, vol. 13, pp. 108-113, 1997.

[2] D. Janoff, M. Nigel, D. Janardhan, "Prediction of cool down times and designing of insulation for subsea production equipment", The Offshore Technology Conference, Houston, Texas, USA, May 2004. http://dx.doi.org/10.4043/16507-MS

[3] K. A. Aarnes, J. Lesgent, J. C. Hübert, "Thermal design of a Dalia SPS deep-water Christmas tree -verified by use of full scale testing and numerical simulations", The Offshore Technology Conference, Houston, Texas, USA, May 2005. http://dx.doi.org/10.4043/17090-MS
[4] J. Davalath, K. Stevens, "Cool Down Thermal Performance of Subsea Systems Based on Gulf of Mexico Field Experience", The Offshore Technology Conference, Houston, Texas, USA, May 2006. http://dx.doi.org/10.4043/17972-MS

[5] S. Sorbye and M. Randi, "A system design approach for thermal insulation of subsea equipment using CFD", The $8^{\text {th }}$ Biennial ASME Conference on Engineering Systems Design and Analysis, Torino, Italy, July 2006.

[6] D. Carré and J. O'Sullivan, "Moho Bilondo: Subsea Production System Experience", The Offshore Technology Conference, Houston, Texas, USA, May 2009. http://dx.doi.org/10.4043/ 20280-MS

[7] Y. J. Lu, E. Marotta, H. B. Skeels, "CFD thermal analysis of subsea equipment and experimental validation", The Offshore Technology Conference, Houston, Texas, USA, May 2011. http://dx.doi.org/10.4043/21553-MS

[8] K. Asteriadou, A. P. M. Hasting, M. R. Bird, and J. Melrose, "Computational fluid dynamics for the prediction of temperature profiles and hygienic design in the food industry," Food and Bioproducts Process, vol. 84, pp. 157-163, 2004. http://dx.doi.org/10.1205/fbp.04261

[9] K. Ding, H. W. Zhu, J. S. Hao, and J. H. Zhang, "Numerical study on heat transfer and thermal insulation of Subsea Christmas Tree connectors," Petroleum Drilling Techniques, vol. 40, pp. $121-125,2012$.

[10] T. Defraeye and B. Blocken, "CFD analysis of convectice heat transfer at the surfaces of a cube immersed in a turbulent boundary layer", Internatioal Journal of Heat and Mass Transfer, vol. 53, pp. 297-308, 2010. http://dx.doi.org/10.1016/j.ijheatmass transfer.2009.09.029

[11] A. K. De, A, Dalal, "Numerical simulation of unconfined flow past a triangular cylinder", International Journal of Numerical Methods in Fluid, vol. 52, pp. 801-821, 2006. http://dx.doi.org/10.1002/fld.1210

\section{AUTHORS}

Kuang Ding is with College of Mechanical and Transportation Engineering, China University of PetroleumBeijing, Beijing, 102200, China. (e-mail: wszg001@163.com).

Hongwu Zhu is with College of Mechanical and Transportation Engineering, China University of Petroleum-Beijing, Beijing, 102200, China (e-mail: zhuhw@cup.edu.cn).

Xiangling Kong is with China Petroleum Technology and Development Corporation, Beijing, 100028, China (e-mail: kongx11222@yahoo.com.cn).

Biao Hu is with China University of PetroleumBeijing, Beijing, China. (e-mail: wxhubiao@126.com).

The research is supported by the National High Technology Research and Development Program of China (863 Project) (No. 2012AA09A204). This article is an extended and modified version of a paper presented at the International Conference on Mechanical Engineering, Automation and Material Science (MEAMS2012), held 22-23 December 2012, Wuhan, China. Received 14 February 2013. Published as resubmitted by the authors 25 March 2013. 